\title{
The Theory of Dynamic Public Transit Priority with Dynamic Stochastic Park and Ride
}

\author{
Chengming Zhu, ${ }^{1,2}$ Yanyan Chen, ${ }^{1}$ and Changxi $\mathrm{Ma}^{3}$ \\ ${ }^{1}$ Transportation Research Center, Beijing University of Technology, Beijing 100124, China \\ ${ }^{2}$ College of Energy Science and Engineering, Henan Polytechnic University, Jiaozuo, Henan 454000, China \\ ${ }^{3}$ School of Traffic and Transportation, Lanzhou Jiaotong University, Lanzhou, Gansu 730070, China \\ Correspondence should be addressed to Chengming Zhu; zhuchengming@hpu.edu.cn
}

Received 2 December 2013; Revised 24 January 2014; Accepted 10 February 2014; Published 12 March 2014

Academic Editor: Wuhong Wang

Copyright (C) 2014 Chengming Zhu et al. This is an open access article distributed under the Creative Commons Attribution License, which permits unrestricted use, distribution, and reproduction in any medium, provided the original work is properly cited.

Public transit priority is very important for relieving traffic congestion. The connotation of dynamic public transit priority and dynamic stochastic park and ride is presented. Based on the point that the travel cost of public transit is not higher than the travel cost of car, how to determine the level of dynamic public transit priority is discussed. The traffic organization method of dynamic public transit priority is introduced. For dynamic stochastic park and ride, layout principle, scale, and charging standard are discussed. Traveler acceptability is high through the analysis of questionnaire survey. Dynamic public transit priority with dynamic stochastic park and ride has application feasibility.

\section{Introduction}

There is a fact that public transit cannot compete with car and travelers are not willing to initiatively reduce car use. Public transit travelers make effort for relieving traffic congestion, but they do not benefit from their behaviors. Car travelers increase traffic congestion degree and they benefit from their behaviors. Because of the above reason, travelers are reluctant to actively cooperate with government and traffic administration. For travel behavior intervention, there is a large gap between actual effect and expected effect. Some tough intervention measures on car use are adopted for relieving congestion, but tough intervention measures are easily to cause traveler's antipathy and cannot guide traveler to initiatively reduce car use.

The effective travel intervention measure should be able to make public transit to compete with car. Also, it should be able to make government, traffic administration, and public transit traveler (including travels who initiatively reduce car use) to compete with traveler who do not reduce car use. Therefore, it is needed that public transit traveler are willing to actively cooperate with government and traffic administration. The premise of this cooperation is that public transit travelers benefit from choosing public transit. But at present time, public transit traveler cannot benefit from choosing public transit because of very low comfort level and low carrying speed. Therefore, other travel behavior intervention model is needed to be studied based on enhancing public transit travel service level. It should increase public transit competiveness with car and it should ensure that travelers are willing to accept it. It can promote traveler actively to cooperate with government and traffic administration. The start point of this intervention model is based on the fact that public transit travel cost is not higher than car travel cost.

\section{The Existing Problem}

2.1. The Existing Problem of Current Public Transit Priority. There are many researches on public transit priority from a different point. Tirachini et al. [1] have studied restating modal investment priority with an improved model for public transport analysis. Eichler and Daganzo [2] have researched Bus lanes with intermittent priority. Koehler and Kraus Jr. [3] have studied simultaneous control of traffic lights and bus departure for priority operation. Sun et al. [4] have studied bus detection based on sparse representation for transit signal 
priority. Wahlstedt [5] analyzed the impacts of bus priority in coordinated traffic signals. Liu et al. [6] proposed an Elastic analysis on urban public transport priority in Beijing. Zyryanov and Mironchuk [7] studied intermittent bus lane and bus signal priority strategy by simulation. Vedagiri and Arasan [8] discussed on estimating modal shift of car travelers to bus on introduction of bus priority system. The above researches play an important role on public transit priority, but some problems exist. The above researches mainly focus on public transit priority measures, but the research on public transit priority level for specific city is absent. The researches on public transit priority are not discussed from the point of public transit travel cost comparing with car travel cost, which results in low acceptance level of car user on public transit. Then the expected effect of public transit priority cannot be achieved.

Public transit priority policy has been implemented in China for more than ten years, it enhances public transit travel proportion in a certain extent, but traffic congestion is not relieved and car travel proportion during peak period is still increasing. Instead, public transit priority attracts slow travel group to public transit. The nature reason of this result lies in that public transit travel service level is far lower than cars during period. There is no reference point for public transit priority and what priority extent should be achieved for specific city is not discussed, which directly results in no goal of public transit priority and little effect of easing traffic congestion. The key reason is that how to attract car traveler to choose public transit is not considered from traveler point. Simply low fare is proved to be insufficient. Therefore, public transit travel service level should be enhanced through public transit priority. Since passenger crowd level is difficult to be eased in a short period, enhancing carrying speed of public transit is an important goal of public transit priority. Also, carrying speed enhancement for public transit is relative to car carrying speed, rather than simply comparing with carrying speed of public transit itself. It is obvious that public transit carrying speed should dynamic change according to car carrying speed and actual traffic volume. Therefore, dynamic public transit priority theory is needed.

\subsection{The Present Situation and Existing Problem of Inter-} vention on Car Use. The intervention on car use includes policy intervention and driving behavior intervention. For driving behavior intervention, Wang et al. $[9,10]$ discussed model-based digital driving dependability and safety-based behavioural approaching model. This study focuses on policy intervention. The current policy intervention measures include restriction pass, congestion charging, and increasing parking fee. These measures play a certain role to ease traffic congestion in a short period, but they are not suitable for long period because they are difficult to make traveler to initiatively voluntarily cooperate with traffic administration. Borjesson et al. [11] analyzed the Stockholm congestion charges, 5 years on effects, acceptability, and lessons learnt. But current research neglects the study of traveler acceptance on intervention measures. Traveler has low acceptability on intervention measures and is easy to form psychological resistance. These measures are not analyzed from convenient travel perspective. Also, because public transit service level is too low, there is no travel mode which car traveler can accept when reducing car use is required or car use is restricted in certain time interval. Therefore, other intervention measures on car use with higher traveler acceptability should be studied and dynamic public transit priority combined with dynamic stochastic park and ride is an intervention measure with high studying value.

2.3. The Present Situation and Existing Problem of Park and Ride. There are many researches on park and ride from a different point. Holguin-Veras et al. [12] studied user rationality and optimal park-and-ride location under potential demand maximization. Aros-Vera et al. [13] discussed pHub approach for the optimal park-and-ride facility location problem. Farhan and Murray [14] used a multiobjective spatial optimization model for siting park-and-ride facilities. Meek et al. $[15,16]$ analyzed UK local authority attitudes to park and ride and evaluating alternative concepts of busbased park and ride. Kepaptsoglou et al. [17] analyzed optimizing pricing policies in park-and-ride facilities: a model and decision support system with application. Qin et al. [18] analyzed park-and-ride decision behavior based on Decision Field Theory. Hounsell et al. [19] studied enhancing park and ride with access control.

The above researches focus on the layout around rail transit station of urban peripheral or some public transit hub. This layout model plays a certain role for reducing car volume of driving into city center, but it is not conducive for traveler to stochastic selecting park and ride according to their travel demand. Therefore, it can influence the proportion of actual park and ride to possible park and ride. The layout and scale of park and ride should be hierarchical and classified in order to be adapted to dynamic stochastic park and ride demand for car traveler.

\section{Dynamic Public Transit Priority Theory}

3.1. The Connotation of Dynamic Public Transit Priority. Dynamic public transit priority dynamically adjusts spacetime resources for public transit according to road traffic volume and saturation, public transit vehicle volume, and intersection saturation. It includes public transit lane allocation on road, intersection entrance lane, and pass time allocation for public transit at intersection. Its purpose is to ensure that public transit carrying speed is so high that public transit can compete with car. When travelers select public transit, their profits are not lower than car traveler, or public transit travel cost is not higher than car travel. The connotation of dynamic public transit priority can be concretely expressed as follows.

(1) For unit travel distance, the proportion of public transit travel profit to cost is not lower than car travel.

(2) For same travel distance, public transit travel cost is not higher than car travel cost.

Dynamic public transit priority theory is conducive to promote car traveler to reduce car use and shift to public transit. 
3.2. The Level of Dynamic Public Transit Priority. The level of dynamic public transit priority refers to what real-time dynamic priority level should be provided for public transit according to dynamic traffic demand under certain road traffic facilities conditions. That is how to dynamically allocate time and space for public transit priority pass. At the same time, dynamic public transit priority is relative to car travel service level (an average carrying speed of car). The purpose of dynamic public transit priority is to realize that public transit travel cost is not higher than car travel cost. Therefore, the key of dynamic public transit priority is to determine the proportion of public transit carrying speed to car carrying speed. Because car carrying speed is influenced by the saturation of road and intersection, the carrying speed of public transit dynamic changes too. This is the essential connotation of dynamic public transit priority.

\subsubsection{The Equilibrium Point of Public Transit Priority Carry-} ing Speed (The Minimum Carrying Speed). Judging current public transit priority, key factor influencing public transit priority effect is carrying speed. Enhancing public transit carrying speed is a powerful measure for enhancing public transit competitiveness. Therefore, dynamic public transit should ensure that public transit carrying speed is higher than car carrying speed. Because car speed is influenced by traffic saturation, the carrying speed of dynamic transit priority also should be depended on specific traffic saturation.

Assume that public transit travel and car travel have same travel OD and approximate same travel path. That is travel distance of two travel modes is approximately equal. From the point of travel cost, what carrying speed should be provided for public transit is analyzed under certain roadtraffic facilities and traffic saturation.

The travel cost of choosing public transit is $C_{P}$. It includes time $\operatorname{cost} C_{P}^{t}$ (including walking time of arriving at station, away from station, transfer, and waiting time) and ticket cost $C_{P}^{e}$, the energy consumption cost caused by the crowd in public transit and energy consumption cost per unit time $C_{P}^{n}$, without considering energy consumption cost of walking (this walking can be regarded as a kind of physical training).

The travel cost of choosing car is $C_{C}$. It includes time cost $C_{C}^{t}$, fuel cost $C_{C}^{f}$, and parking cost $C_{C}^{p}$.

Note that travel distances are $L$, walking distance of choosing public transit is $L_{W}$, walking speed is $V_{W}$, public transit carrying speed is $V_{P}$, car carrying speed is $V_{C}$, and fuel cost of per $\mathrm{km}$ is $C_{0}^{f}$.

For the same traveler, per time cost of choosing public transit and car is equal. Assume that Per time cost is $C_{0}^{t}$, then travel cost of choosing public transit is as shown in (1):

$$
\begin{aligned}
C_{P} & =C_{P}^{t}+C_{P}^{e}+C_{P}^{n} \cdot \frac{L-L_{W}}{V_{P}} \\
& =C_{0}^{t} \cdot\left(\frac{L_{W}}{V_{W}}+T_{W}+\frac{L-L_{W}}{V_{P}}\right)+C_{P}^{e}+C_{P}^{n} \cdot \frac{L-L_{W}}{V_{P}} .
\end{aligned}
$$

Travel cost of choosing car is as shown in (2):

$$
C_{C}=C_{C}^{t}+C_{C}^{f}+C_{C}^{p}=C_{0}^{t} \cdot \frac{L}{V_{C}}+C_{0}^{f} \cdot L+C_{C}^{p} .
$$

Under real-time dynamic traffic flow conditions, the relationship model between $V_{P}$ and $V_{C}$ is obtained in (3) according to $C_{P}=C_{C}$ :

$$
V_{P}=\frac{\left(C_{0}^{t}+C_{P}^{n}\right) \cdot\left(L-L_{W}\right) V_{W} V_{C}}{C_{0}^{t} L V_{W}+\left[\left(C_{0}^{f} L+C_{C}^{p}-C_{P}^{e}-C_{0}^{t} T_{W}\right) V_{W}-C_{0}^{t} L_{W}\right] V_{C}} .
$$

Car speed is average speed and it is related to road traffic flow density and waiting time at intersection. The model between $V_{C}$ and road traffic flow density $K$ and waiting time $T_{D}$ at intersection will be constructed. Assume that speed is a linear relationship with density, which is shown in (4). Limitation Assume that high speed of urban road is $V_{f}$, jam density is $K_{j}$, and the travel speed of car is $V_{R}$, then

$$
\begin{gathered}
V_{R}=V_{f}\left(1-\frac{K}{K_{j}}\right), \\
V_{C}=\frac{L V_{f}\left(K_{j}-K\right)}{L K_{j}+T_{D} V_{f}\left(K_{j}-K\right)} .
\end{gathered}
$$

Put (5) to (3), then

$$
\begin{aligned}
V_{P}= & \left(\left(C_{0}^{t}+C_{P}^{n}\right) \cdot\left(L-L_{W}\right) V_{W} \cdot \frac{L V_{f}\left(K_{j}-K\right)}{L K_{j}+T_{D} V_{f}\left(K_{j}-K\right)}\right) \\
& \times\left(C_{0}^{t} L V_{W}+\left[\left(C_{0}^{f} L+C_{C}^{p}-C_{P}^{e}-C_{0}^{t} T_{W}\right) V_{W}-C_{0}^{t} L_{W}\right]\right. \\
& \left.\frac{L V_{f}\left(K_{j}-K\right)}{L K_{j}+T_{D} V_{f}\left(K_{j}-K\right)}\right)^{-1} \cdot
\end{aligned}
$$

From the above model, it is shown that if parking cost $C_{C}^{p}$, walking distance $L_{W}$, walking speed $V_{W}$, and fuel cost $C_{0}^{f}$ of per $\mathrm{km}$ and ticket cost are invariable, when the travel cost of choosing public transit and choosing car is equal for the same travel distance, public dynamic $V_{P}$ is determined by car flow density, car waiting time at intersection, and energy consumption cost per unit time. Energy consumption cost per unit time is the function of crowding degree $J$ in public transit. Therefore, $V_{P}$ is the level of dynamic public transit priority.

\subsubsection{The Public Transit Priority Demand Based on Minimum} Carrying Speed. According to above priority level, road lane numbers of one direction, intersection form, entrance lane, and passing time for public transit priority can be determined. For public transit, the necessary driving speed on road and allowable waiting time at intersection can be 


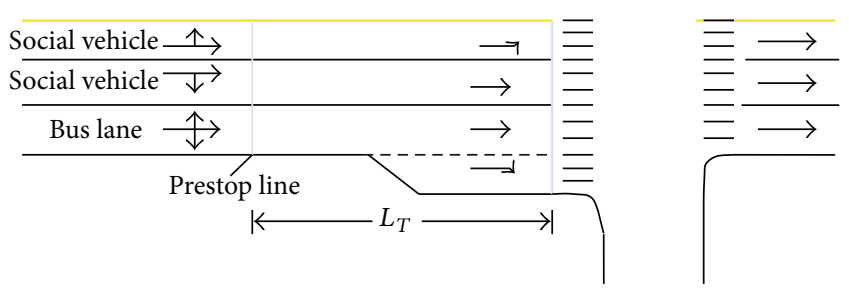

Figure 1: Traffic organization design sketch of dynamic public transit priority.

deduced from public route number $N$, departure interval $\tau$, stop time $S_{T}$ at station, and average spacing between intersection. Necessary public transit lane number can be determined by the necessary driving speed on road and public transit volume. The pass rule for public transit priority can be determined by allowable waiting time at intersection.

For public transit, the available passing time $T_{R}$ on road and waiting time $T_{J}$ at intersection are analyzed firstly:

$$
T_{R}+T_{J}=\frac{L}{V_{P}}-\frac{L}{d} \cdot S_{T}
$$

Actually, the travel speed of public transit on public transit lane can reach $V_{R}$, thus,

$$
T_{J}=\frac{L}{V_{P}}-\frac{L}{d} \cdot S_{T}-T_{R}
$$

It is obvious that available waiting time $T_{J}$ at intersection is related to carrying speed $V_{P}$ and stop time $S_{T}$. The longer $T_{R}$ and $S_{T}$ are, the shorter $T_{J}$ is. Intersection signal timing is mainly determined by $T_{J}$.

Generally, one public transit lane is enough on road and two public transit lanes is needed at intersection under general condition. Stop line in advance is designed for public transit and car. Specific traffic organization and design is showed as Figure 1.

\subsection{Dynamic Traffic Organization and Design of Dynamic} Public Transit Priority. The dynamic traffic organization and design of dynamic public transit priority mainly include variable public transit lane design, pass space, and stop rule design at intersection and signal timing design. Variable public transit lane design is deduced from above model, with setting variable public transit lane sign and releasing information about variable public transit lane in advance in order to enable car traveler to select appropriate path or park and ride in advance. Two stop lines are adopted at intersection entrance lane. Vehicle firstly stops at stop line far away intersection for prewaiting. Vehicle which will pass intersection in next green signal waits before stop line near intersection. Specific organizational design is as shown in Figure 1.

The distance $L_{T}$ between two stop lines is determined by public transit vehicle volume $Q_{B}$, which needs to pass intersection during one green time and entrance lane numbers $n$ (relating to permit through rule influenced by signal timing).
The space way of public transit vehicle queue is $l_{B}$. The model used to determine $L_{T}$ is as shown in (9):

$$
L_{T}=\frac{Q_{B} l_{B}}{n} .
$$

3.4. Model Analysis. The equation of $C_{P}=C_{C}$ is the basic requirement of dynamic public transit priority. The aim of dynamic public transit priority is to make traveler initiative to choose public transit, but the equation of $C_{P}=C_{C}$ cannot make sure that traveler will prefer to choose public transit, therefore, the equation of $C_{P}=C_{C}$ is adjusted as $C_{P}=K C_{C}$. Here, $K$ is a coefficient. In order to determine $K$, questionnaire survey is carried out in Jiaozuo city. The question is that when the total travel cost including travel economic cost, travel time, and comfort is considered, $R$ is the ratio of public transit travel cost and car travel cost, what value is $R$ ? you will prefer to choose public transit. Two hundred questionnaires are carried out. Questionnaire survey shows that $60 \%$ of travelers choose 70 percentage and $22 \%$ of travelers choose 80 percentage. Therefore, it is rational to let $K=0.7$, then $C_{P}=0.7 C_{C}$. That is,

$$
\begin{gathered}
C_{0}^{t} \cdot\left(\frac{L_{W}}{V_{W}}+T_{W}+\frac{L-L_{W}}{V_{P}}\right)+C_{P}^{e}+C_{P}^{n} \cdot \frac{L-L_{W}}{V_{P}} \\
\quad=0.7\left(C_{0}^{t} \cdot \frac{L}{V_{C}}+C_{0}^{f} L+C_{C}^{p}\right) .
\end{gathered}
$$

Here, $L$ is average travel distance, $T_{W}$ is waiting time. For Jiaozuo city, average travel distance is $6 \mathrm{~km}, L_{W}$ is $0.6 \mathrm{~km}, T_{W}$ is $12 \mathrm{~min}, C_{P}^{e}$ is 1 yuan, $C_{0}^{f}$ is 0.7 yuan, $V_{C}$ is $22.9 \mathrm{~km}, C_{C}^{p}$ is 5 yuan, $C_{0}^{t}$ is 10 yuan, and $C_{P}^{n}$ is 8 yuan. Then according to (10), $V_{P}$ can be calculated. $V_{P}=25.116 \mathrm{~km} / \mathrm{h}$. It is the level of dynamic public transit priority when the car carrying speed is $22.9 \mathrm{~km}$.

But according to survey, actual $V_{P}$ is $12.92 \mathrm{~km} / \mathrm{h}$. Now, $V_{P}$ is difficult to be increased in Jiaozuo city; according to (10), $C_{C}^{p}$ should be raised to 10 yuan.

\section{Dynamic Stochastic Park and Ride Theory}

4.1. The Connotation of Dynamic Stochastic Park and Ride. Current park and ride generally lies in urban peripheral. For urban center with serious traffic congestion, firstly, it is necessary to encourage traveler to reduce car use as far as possible, secondly, park and ride should be provided for traveler who have selected car when they feel too crowd. Also when dynamic public priority is carried out, some traveler of using car will want to park and ride because car carrying speed is lower than public transit carrying speed, then it is needed to provide parking facility for park and ride. This park and ride facility is located around general public transit station, with smaller scale comparing with general park and ride facility. Therefore, it is different from general park and ride. When dynamic public priority is carried out, not only public transit carrying speed is guaranteed, but also other choices are provided for car traveler on road. This intervention measures can be willingly accepted by traveler. 


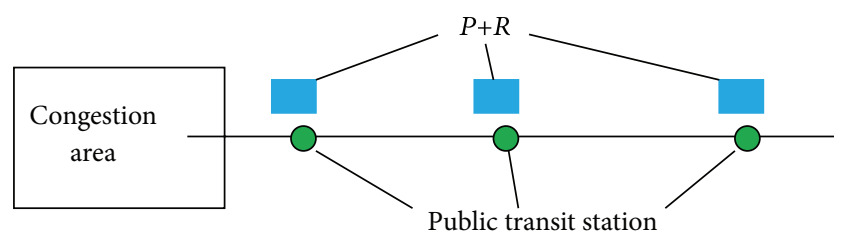

FIGURE 2: The layout sketch of dynamic stochastic park and ride.

When traveler has selected car and drives on road, at the beginning stage of travel, traveler is not sure that park and ride is necessary. If park and ride is needed, which site will be selected is not clear too. These are related to real-time dynamic traffic condition. That is, whether park and ride is needed and which park and ride site is selected is determined by dynamic traffic condition, which means that this park and ride has dynamic. Also it is obvious that this park and ride has uncertainty, which means it is stochastic. Therefore, this park and ride is called dynamic stochastic park and ride. At the same time, the above dynamic public transit priority will promote travel behavior of dynamic stochastic park and ride.

\subsection{The Layout and Scale of Dynamic Stochastic Park and} Ride. Dynamic stochastic park and ride layout is generally close to public transit station and corresponding road with more traffic volume will be priority selected. Figure 2 is layout sketch.

For dynamic stochastic park and ride, the closer it is to congestion area, the smaller the scale is. The diminishing size method mainly lies in two reasons. First, the closer it is to congestion area, the greater the difficulty of arranging park and ride land is. Second, traveler is encouraged and guided to park and ride in advance as far as it is possible in order to release traffic pressure of road and intersection close to congestion area.

The specific size of dynamic stochastic park and ride is determined by car volume of peak period and corresponding traffic volume with travel destination in congestion area. The corresponding traveler is investigated for park and ride proportion and site. Then, the park and ride volume for each station can be obtained and the park and ride scale for park and ride facility is determined. For car travel destination investigation, license plate photo can be adopted. Each road with park and ride facility should be investigated by license plate photo. The car volume with travel destination at congestion area is analyzed and for each car, whether park and ride will be adopted and which station will be selected are analyzed. If the station number with park and ride facility is $N$, corresponding road section number is $N$ and corresponding intersection number is $N$. The layout sketch and charging standard for different site of dynamic stochastic park and ride are shown for car traveler during investigation (delivering card and feedback).

When investigation is completed, the car volume with passing road Section 1 and travel destination at congestion area are obtained, the park and ride volume at each park and ride facility of this volume, respectively, is $P Q_{1 j}(j=$ $1,2, \ldots, N)$. Car volume entering investigation road section from $i(i=2, \ldots, N)$ intersection combined with travel destination at congestion area is investigated and its ride volume at each park and ride facility is $P Q_{i j}(j=i, \ldots, N)$, then the park and ride volume of $i$ park and ride facility is as shown in (11):

$$
P R^{i}=P Q^{i}=\sum_{j=1}^{i} P Q_{j i} \quad(i=1, \ldots, N) .
$$

Therefore, the $i$ park and ride facility scale can be preliminary determined as ashown in (11).

After $P R^{i}$ is determined, the car volume of each road section during peak period is $Q^{i}=(i=1, \ldots, N)$; when car traveler selects park and ride, the car volume of $i$ road section reduces to as shown in (12):

$$
Q_{P}^{i}=Q^{i}-\sum_{j=1}^{i} P Q_{j i} \quad(i=1, \ldots, N) .
$$

This model can be directly used to analyze $V_{P}$ of dynamic public transit; that is the relationship between dynamic public transit priority and dynamic stochastic park and ride volume is established.

4.3. Charging Standard of Dynamic Stochastic Park and Ride. The charging principle of dynamic stochastic park and ride is lower than charging standard of central area. For park and ride facility, the closer it is to congestion area, the higher the charging standard is. Charging standards of park and ride can be based on the charge standard of congestion area and it is reduced according to the distance of park and ride apart from congestion area. The charging standard of congestion area is $F_{J}$ yuan per hour. The charging standard of the park and ride with large scale at urban peripheral is $F_{E}$ yuan per hour and its distance apart from congestion area is $L_{E J} \mathrm{~km}$; dynamic stochastic park and ride distance apart from congestion area is $L_{P J} \mathrm{~km}$, then corresponding charging standard for park and ride is as shown in (13):

$$
F_{P J}=F_{J}-\frac{F_{J}-F_{E}}{L_{E J}} \cdot L_{P J} \quad \text { yuan per hour. }
$$

4.4. The Guidance for Dynamic Stochastic Park and Ride. The guidance for dynamic stochastic park and ride includes two aspects. On the one hand, it is needed to guide travelers to park and ride in advance as far as possible based on reducing car volume on road; on the other hand, the closer it is to congestion area, the smaller the scale of park and ride is, so, it is needed to guide travelers to park and ride in advance as far as possible based on park and ride capacity. When dynamic public transit priority is carried out, the closer it is to congestion area, the greater the car travel resistance is, and the parking cost is very high in area close to congestion area or in congestion area. The above two factors prompt traveler to park and ride in advance. At the same time, marked sign is set before each park and ride and propaganda slogan are adopted with showing the benefits and charge standard of park and ride. In order to provide convenience for park and 


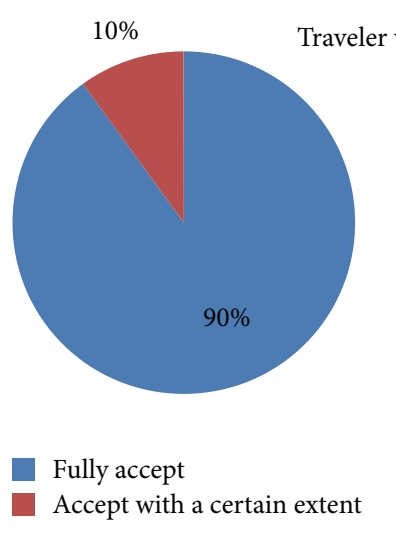

(a)

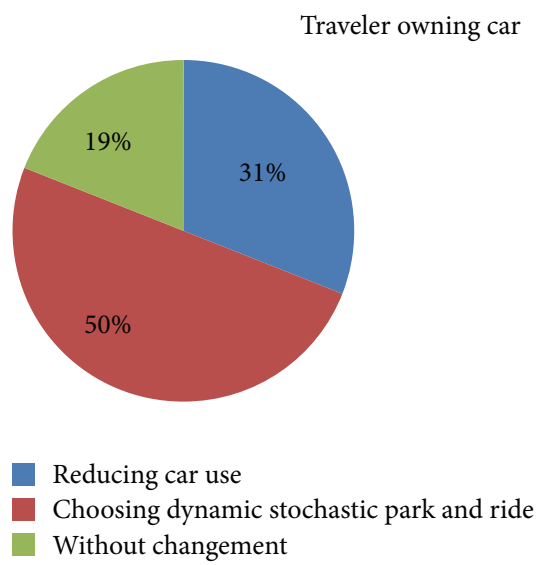

(b)

FIGURE 3: Traveler acceptability on dynamic public transit priority with dynamic stochastic park and ride.

ride traveler to transfer to public transit, public transit station is set at dynamic stochastic park and ride with bigger transfer demand.

\section{Traveler Acceptability Analysis}

The traveler acceptability on dynamic public transit priority with dynamic stochastic park and ride includes public transit traveler acceptability on dynamic public transit priority and car traveler acceptability on dynamic public transit priority with dynamic stochastic park and ride. Acceptability analysis is conducted by questionnaire investigation. The goal of dynamic public transit priority and charging standard of dynamic stochastic park and ride is stated in questionnaire. 300 questionnaires are handed out. One hundred respondents own cars. The result from investigating on traveler without owning car at present shows that ninety percent of them fully accept dynamic public transit priority and ten percent of them, who prepare to buy car recently, accept with a certain extent.

The result from investigating on traveler owning car shows that thirty-one percent of them intend to reduce car use by choosing public transit in peak period, fifty percent of them intend to choose dynamic stochastic park and ride, and nineteen percent of them do not intend to change car use pattern. The result is showed as in Figure 3.

It can be observed from above survey result that traveler has higher acceptability on dynamic public transit priority with dynamic stochastic park and ride. Therefore, dynamic public transit priority with dynamic stochastic park and ride has a good application prospect and it can relieve traffic congestion.

\section{Further Discussion on Dynamic Public Transit Priority}

The above discussion on dynamic public transit priority is mainly from the point of carrying speed, which is mainly from the point of dynamic space-time priority. But sometimes, the expected level of dynamic public transit priority cannot be achieved because of many factors, such as road and traffic condition and car user acceptance. Then, other measures should be adopted in order to achieve the expected level of dynamic public transit priority. Other measures can also be obtained from the point that the travel cost of using public transit is not higher than travel cost of using car. If congestion charging $C_{C}^{c}$ is considered, the travel cost of using car can be modified as follows:

$$
C_{C}=C_{C}^{t}+C_{C}^{f}+C_{C}^{p}+C_{C}^{c}=C_{0}^{t} \cdot \frac{L}{V_{C}}+C_{0}^{f} \cdot L+C_{C}^{p}+C_{C}^{c}
$$

According to $C_{P}=C_{C}$,

$$
\begin{gathered}
C_{0}^{t} \cdot\left(\frac{L_{W}}{V_{W}}+T_{W}+\frac{L-L_{W}}{V_{P}}\right)+C_{P}^{e}+C_{P}^{n} \cdot \frac{L-L_{W}}{V_{P}} \\
=C_{0}^{t} \cdot \frac{L}{V_{C}}+C_{0}^{f} \cdot L+C_{C}^{p}+C_{C}^{c} .
\end{gathered}
$$

In this equation, $L_{W}, V_{P}, C_{P}^{e}, C_{P}^{n}, V_{C}, C_{C}^{p}$, and $C_{C}^{c}$ can be dynamically adjusted.

At present time, for most cities, the adjustable range of $L_{W}, C_{P}^{e}, C_{P}^{n}$ is very small; that is, in order to achieve the equation of $C_{P}=C_{C}, V_{P}, V_{C}, C_{C}^{p}, C_{C}^{c}$ should be key dynamic adjustment parameter.

Based on traveler acceptance, $V_{P}$ and $V_{C}$ should be firstly adjusted. When the equation of $C_{P}=C_{C}$ cannot be achieved, $C_{C}^{p}$ should be adjusted. The last adjustment parameter is $C_{C}^{c}$. For traffic management, the key of dynamic public transit priority is how to achieve the balance among $V_{P}, V_{C}, C_{C}^{p}$, and $C_{C}^{c}$ to make traveler to initiative accept it. This is the emphasis of future research.

\section{Conclusion}

Based on the point that the travel cost of choosing public transit is not higher than the travel cost of choosing car, the real-time dynamic relationship model among public transit 
carrying speed, car carrying speed, and traffic density is established. The model of determining the level of dynamic public transit priority is constructed. For dynamic public transit priority, if parking cost and congestion charge do not reach a certain level, public transit carrying speed must be higher than car carrying speed. Dynamic stochastic park and ride is a matching measure for dynamic public transit priority and its layout and scale have feasibility, with promoting car traveler to dynamic stochastic transfer to public transit. Questionnaire survey shows that traveler has higher acceptability on dynamic public transit priority with dynamic stochastic park and ride and it illustrates that the application of dynamic public transit priority with dynamic stochastic park and ride is feasible. How to achieve the balance among public transit carrying speed, car carrying speed, parking cost, and congestion charging is the emphasis of future research.

\section{Conflict of Interests}

The authors declare that there is no conflict of interests regarding the publication of this paper.

\section{Acknowledgments}

This research is sponsored by Science and Technology Planning Project of Beijing Municipal Science and Technology Commission (no. Z1211000003120100) and the Natural Science Foundation of China (no. 61164003).

\section{References}

[1] A. Tirachini, D. A. Hensher, and S. R. Jara-Díaz, "Restating modal investment priority with an improved model for public transport analysis," Transportation Research E, vol. 46, no. 6, pp. 1148-1168, 2010.

[2] M. Eichler and C. F. Daganzo, "Bus lanes with intermittent priority: strategy formulae and an evaluation," Transportation Research B, vol. 40, no. 9, pp. 731-744, 2006.

[3] L. A. Koehler and W. Kraus Jr., "Simultaneous control of traffic lights and bus departure for priority operation," Transportation Research C, vol. 18, no. 3, pp. 288-298, 2010.

[4] X. . Sun, H. P. Lu, and J. Wu, "Bus detection based on sparse representation for transit signal priority," Neurocomputing, vol. 118, pp. 1-9, 2013.

[5] J. Wahlstedt, "Impacts of bus priority in coordinated traffic signals," Procedia, vol. 16, pp. 578-587, 2011.

[6] M. J. Liu, J. Yang, L. L. Yang, and Z. Zhangb, "An elastic analysis on urban public transport priority in Beijing," Procedia, vol. 42, pp. 79-85, 2012.

[7] V. Zyryanov and A. Mironchuk, "Simulation study of intermittent bus lane and bus signal priority strategy," Procedia, vol. 48, pp. 1464-1471, 2012.

[8] P. Vedagiri and V. T. Arasan, "Estimating modal shift of car travelers to bus on introduction of bus priority system," Journal of Transportation Systems Engineering and Information Technology, vol. 9, no. 6, pp. 120-129, 2009.

[9] W. H. Wang, H. W. Guo, H. Bubb, and K. Ikeuchi, "Numerical simulation and analysis procedure for model-based digital driving dependability in intelligent transport system," KSCE Journal of Civil Engineering, vol. 15, no. 5, pp. 891-898, 2011.
[10] W. H. Wang, W. Zhang, H. W. Guo, H. Bubb, and K. Ikeuchi, "A safety-based approaching behavioural model with various driving characteristics," Transportation Research C, vol. 19, no. 6, pp. 1202-1214, 2011.

[11] M. Borjesson, J. Eliasson, M. B. Hugosson, and K. BrundellFreij, "The Stockholm congestion charges -5 years on. Effects, acceptability and lessons learnt," Transport Policy, vol. 20, pp. $1-12,2012$.

[12] J. Holguin-Veras, W. F. Yushimito, F. Aros-Vera et al., "User rationality and optimal park-and-ride location under potential demand maximization," Transportation Research B, vol. 46, pp. 949-970, 2012

[13] F. Aros-Vera, V. Marianov, and J. E. Mitchell, "p-hub approach for the optimal park-and-ride facility location problem," European Journal of Operational Research, vol. 226, no. 2, pp. 277285,2013

[14] B. Farhan and A. T. Murray, "Siting park-and-ride facilities using a multi-objective spatial optimization model," Computers \& Operations Research, vol. 35, no. 2, pp. 445-456, 2008.

[15] S. Meek, S. Ison, and M. Enoch, "UK local authority attitudes to Park and Ride," Journal of Transport Geography, vol. 18, no. 3, pp. 372-381, 2010.

[16] S. Meek, S. Ison, and M. Enoch, "Evaluating alternative concepts of bus-based park and ride," Transport Policy, vol. 18, no. 2, pp. 456-467, 2011.

[17] K. Kepaptsoglou, G. K. Matthew, and Z. Z. Li, “Optimizing pricing policies in Park-and-Ride facilities: a model and decision support system with application," Journal of Transportation Systems Engineering and Information Technology, vol. 10, no. 5, pp. 53-65, 2010.

[18] H. M. Qin, H. Z. Guan, and Y. J. Wu, "Analysis of parkand-ride decision behavior based on Decision Field Theory," Transportation Research F, vol. 18, pp. 199-212, 2013.

[19] N. Hounsell, B. Shrestha, and J. N. Piao, "Enhancing Park and Ride with access control: a case study of Southampton," Transport Policy, vol. 18, no. 1, pp. 194-203, 2011. 


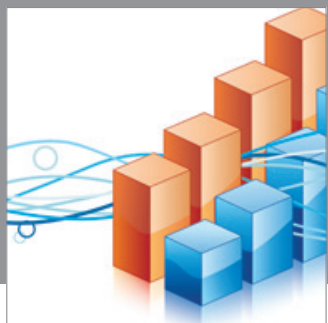

Advances in

Operations Research

mansans

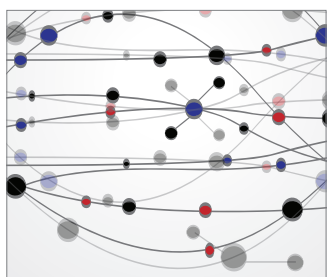

The Scientific World Journal
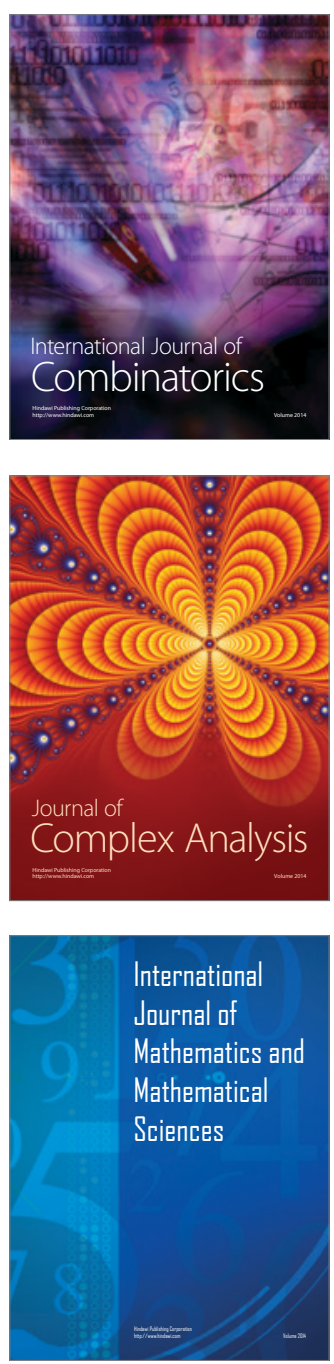
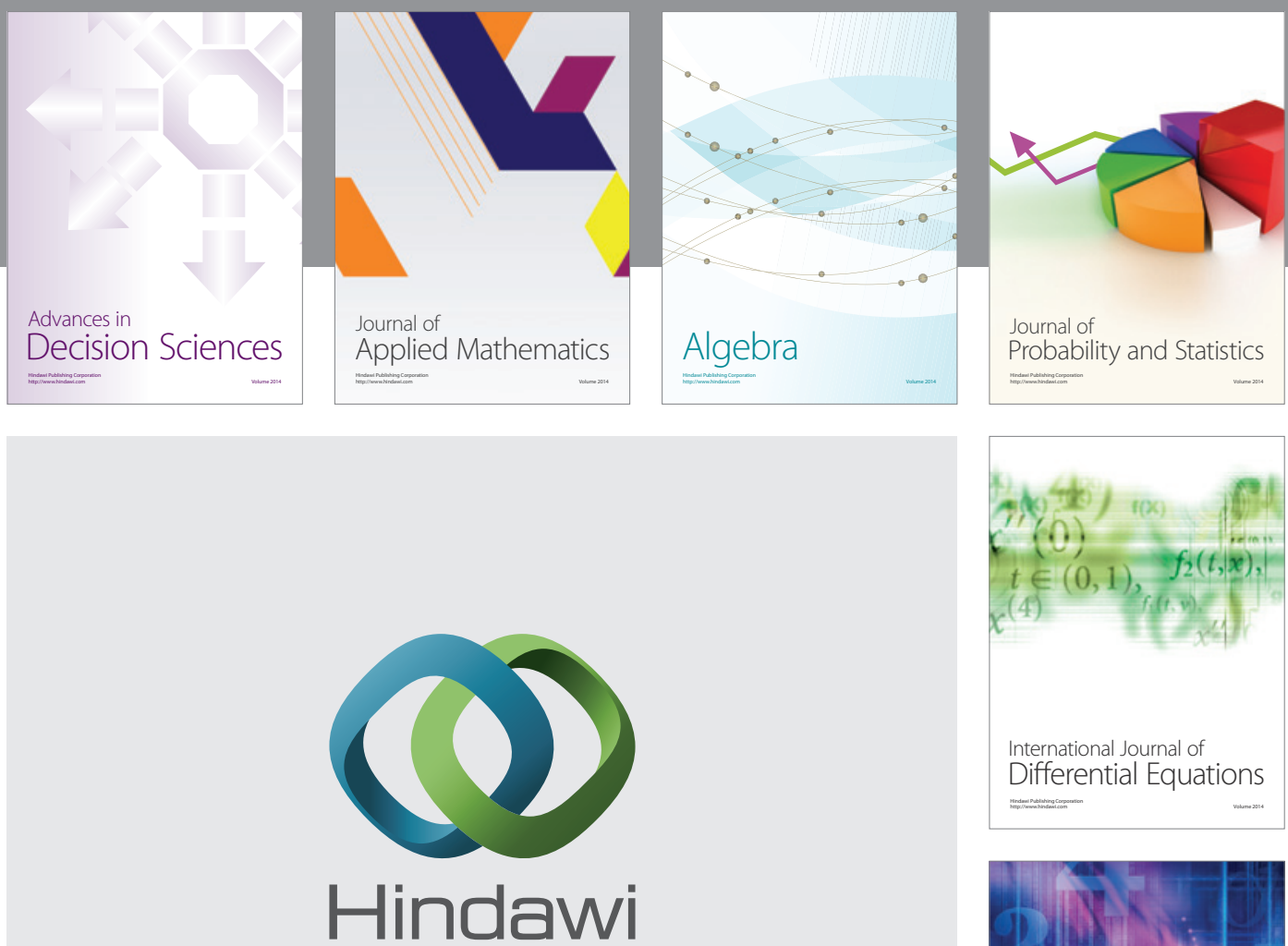

Submit your manuscripts at http://www.hindawi.com
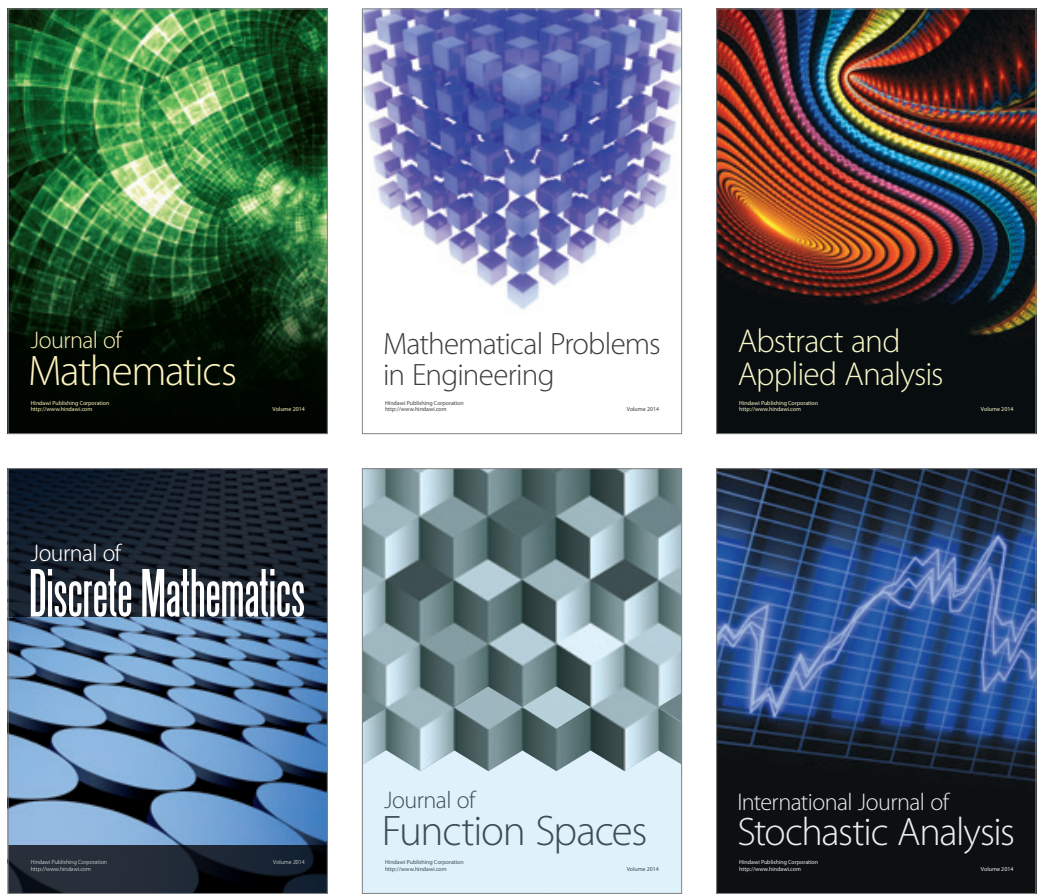

Journal of

Function Spaces

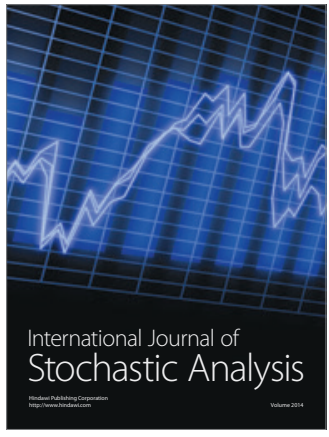

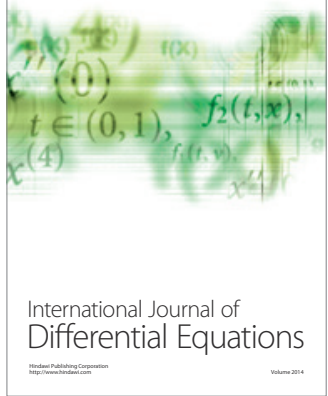
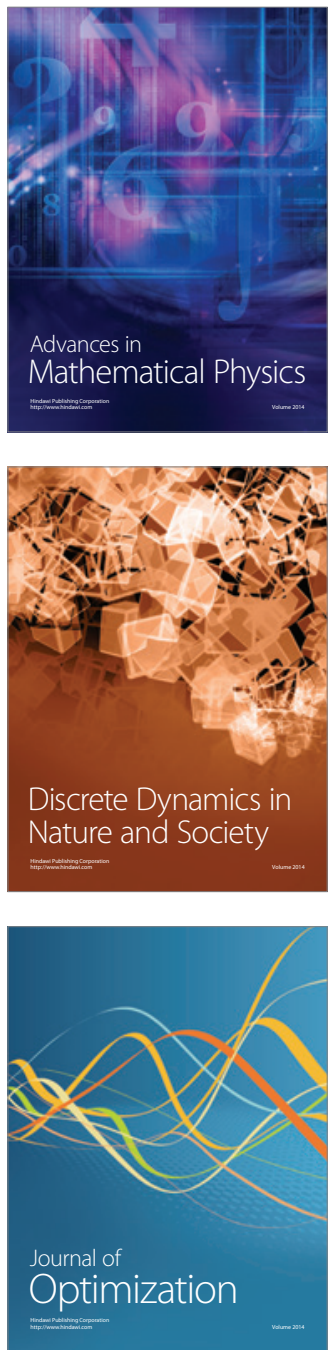